The Eurasia Proceedings of Educational \& Social Sciences (EPESS), 2016

Volume 5, Pages 125-134

ICRES 2016: International Conference on Research in Education and Science

\title{
VIDEO CAPTURED LECTURES WITH SALAZAR'S METHOD OF GROUPING: EFFECTS ON STUDENTS'ACHIEVEMENT IN DIFFERENTIAL CALCULUS
}

\author{
Douglas A. Salazar \\ Ama International University -Bahrain
}

\begin{abstract}
This study aimed to raise the achievement level of students in Differential Calculus using Video Captured Lectures with Salazar's Method of Grouping. Using the quasi-experimental method of research, this study employed the qualitative and quantitative analysis relative to data generated by the Achievement Test and Math Journal with follow-up interview. Within the framework of the limitations of the study, the video captured lectures with enhanced groupings revealed a significant difference on the gain scores between the two groups and a significant difference within and between groups (control and experimental) on the student scores in the Achievement test. Although, the results revealed a failure mark on the pretest but a significant increase of the gain scores was achieved in the posttest. Specifically, an average increase was gained by the control group and a high increase was gained in the experimental group, credited to the actual video captured lectures. It is therefore possible to improve the student achievement level in Differential Calculus using the video captured lectures with Salazar's Method of Grouping. Moreover, qualitative assessments showed that Salazar's Method of Grouping creates and develops self-confidence, encourages effective communication and facilitates exchange of ideas towards a common goal. However, the students from the experimental group suggested in enhancing the actual video captured lectures in terms of audio and visual presentations.
\end{abstract}

Keywords: Video captured lectures, salazar's grouping method and achievement in differential calculus

\section{Introduction}

Typically, students are interested in using new technology like mobile phones, tablet computer, game computers, iTunes, video recordings, iPhones,iPads,iPods, and social media programs like face book, twitter, instagram, you tube and flicker. Therefore, there is a demand for creation of tools that enable students to learn according to their current habits, at their own pace and time.

Video recorded lectures offer flexible education tailored for increasing academic success since the difficult course are recorded enabling anywhere, anytime access at any pace, time and place (Bagutakayo, 2011). Lecture capture means recording classroom-based activities in a digital format that students can then watch over the web, on a computer or their mobile device. Lecture capture technology records the presenter's audio and video, as well as any visual aids - laptop, tablet, whiteboard, document camera, visualize - synchronizes them, and webcasts the stream live or archives for on-demand playback (White, 2014).

Recently, Salazar's (2013) study revealed a no significant difference on the gain scores obtained by the students exposed to Salazar's Method of Grouping in a flipped classroom and Small Grouping Method. However, qualitative results revealed that Salazar's Method of Grouping in a flipped classroom encouraged the students to solve problems by themselves, share and help others in the next stages. The incentives served as a driving force to solve the problems on the seatwork stage. Furthermore, the students suggested to use actual video recorded lectures of the professor rather than using shared videos in the face book from the You tube. The video lectures from the You Tube were of different styles in differentiating functions compared to their professor method that made them confused. Furthermore, not all students watched the videos at home for some personal reasons.

\footnotetext{
- This is an Open Access article distributed under the terms of the Creative Commons Attribution-Noncommercial 4.0 Unported License, permitting all non-commercial use, distribution, and reproduction in any medium, provided the original work is properly cited.

- Selection and peer-review under responsibility of the Organizing Committee of the conference

*Corresponding author: Douglas A. Salazar- E-Mail: salguodrazalas@yahoo.com
} 
Thus, the researcher in this study used videotaped of actual lectures (video captured lectures) of the teacher, then play the recorded video in the experimental group. Furthermore, the video captured lectures were posted in the researcher face book page created for the students in the experimental group only. It is a closed group where they are instructed not to share and download the video captured lectures. The experimental group was exposed to enhanced method of grouping.

\section{Statement of the Problem}

This study used actual video captured lectures with Salazar's Method of Grouping to determine the effects on students 'achievement level in Differential Calculus.

Specifically, this study answered the following questions;

What is the students 'achievement level in Differential Calculus?

Is there a difference in the achievement level of the students after exposing them to the traditional method (instructor based) and video captured lectures with Salazar's Method of Grouping?

What are the gain scores of the students' achievement level in Differential Calculus?

Is there a difference in the gain scores in the achievement test of students after exposing them to the traditional method (instructor based) and video captured lectures with Salazar's Method of Grouping?

What insights are drawn from the students 'journal/interview?

\section{Research Hypothesis}

There is a significant difference in the mean scores (within and between groups) in the achievement test of students exposed to traditional method (Instructor based) and Salazar's method of grouping using video captured lectures.

There is a significant difference in the mean gain scores in the achievement test of students exposed traditional method (Instructor based) and Salazar's Method of grouping using video captured lectures.

\section{Significance of the Study}

The main purpose of the study is to raise the achievement level of students in Differential Calculus.

Results of this study will encourage Calculus teachers to use lecture capture technology with enhanced method of grouping, if found effective.

This study is beneficial to students who valued sharing and helping others, exchange of ideas and effective communication among their classmates and in turn become fruitful citizens in this country.

Insights drawn from this study will guide mathematics teachers in teaching Calculus and inspire them to conduct researches on strategies in teaching mathematics.

This study will also encourage administrators to recommend to his teachers the possibility of using lecture capture technology with Salazar's method of grouping.

\section{Scope and Limitations of the Study}

This study used the Video Captured Lectures with Enhanced Method of Groupings and the Traditional Method (Instructor Based) to raise the students' achievement level in Differential Calculus. The validated Achievement Test and Math Journal used by Salazar's (2012) were used in this study. This study was conducted in an International University- Bahrain, first trimester, school year 2015-2016, to avoid the Ramadan Timing which is one of the factors of students' absences and low performance in class. The subjects of the study were the two (2) existing combined classes of second year Bachelor of Science in Mechatronics Engineering (BSME), Bachelor of Science in Computer Science (BSCS) and Bachelor of Science in Engineering Informatics (BSEI) students who were officially enrolled in Math 406 (Differential Calculus with Analytic Geometry). The experiment focused only on the differentiation of functions (algebraic and transcendental) which was part of the lessons for the midterm period. The researcher himself handled the experiment. To ensure that the video captured lectures be viewed by the students in the experimental group only, a closed group in the face book was created. Only the students in the experimental group were accepted as friends and videos were set to friends only. Furthermore, 
they were instructed not to share and/or download the videos, otherwise they will earn minus points. Constant monitoring was conducted.

\section{Definition of Terms}

The following important terms are operationally and/or conceptually defined as used in this study.

Achievement in Differential Calculus - refers to the performance of the student respondents in the Achievement Test in Differential Calculus.Achievement Level- this is the interpretation of the student scores and gain scores based on the AMAIUB University grading system (Student Handbook)

Achievement Test - the test used by Salazar's (2012) study .

Control group - the group of students that were exposed to traditional method (Instructor Based).

Experimental group - the group that were exposed to Video Captured Lectures with Salazar's Method of Groupings.

Gain Scores - it refers to the increase in score of the control and experimental groups from pretest to post test. Math Journals - refers to the written impressions, comments and suggestions of the students in regards to the method of teaching, use of video captured lectures and incentives given as used in this study. The same also serve as the guide questions for the interview.

Mechatronics/Informatics/Computer Science students - refers to the students officially enrolled in Math 406 (Differential Calculus with Analytic Geometry), first trimester, AY 2015-2016.

Video Captured Lectures -It refers to the actual lecture captured in the control group and were watched by the students in the experimental group. However, questions, clarifications and additional examples were given.

Salazar's Method of Grouping- On the seatwork stage in the experimental group, Salazar's Method of Grouping was used. That is, the first stage was Individual Learning. As soon as the student successfully defended his solution in class and earns the teacher signature, he was instructed to select a group member of his choice and proceed to the next problem. Whenever, the same group (with two members) was able to defend their solution in class successfully, each group member earned the teacher signature. Then they must select another group member of their choice and move to the next problem. Solving the problem was group effort. If again, the group with three (3) members successfully defended their solution, and each group member earned the teacher signature, and then returns to stage one. This cycle continued until the end of the experiment. However, membership of groups must not be the same on the next groupings. When all the students have belong to a group of two or three, the said group returned to stage one. The accumulated teacher's signature was counted as additional points and be added on the student's final project and/or class participation grade in the finals.

Traditional Method (Instructor Based): An actual lecture traditionally used by the researcher was used. The students solved the seatwork individually. The teacher moved around to assist or give hints and suggestions on how to solve a particular problem whenever necessary. Sometimes the students approached the teacher, show their work and ask for hints. The first students, who presented a correct solution and answer to the teacher, presents and defend his solution on the board and earned the teacher signature. However, a grace period of five (5) to ten (10) minutes were given to give chances to others who are still solving the problem before the solution was discussed on the board. The same earned the teacher signature. The accumulated teacher's signature was ranked and was counted as additional points in their final project and/or class participation grade in the finals.

The posttest was administered after the experiment. The math journal were given a day before the posttest. As soon as the students submitted their Math journal, follow-questions were asked (interview) to the subjects of the study.

\section{Methods}

The research design employed the quasi-experimental method. This study is a qualitative and quantitative experimental research.

The research design of this study is shown in the diagram below:

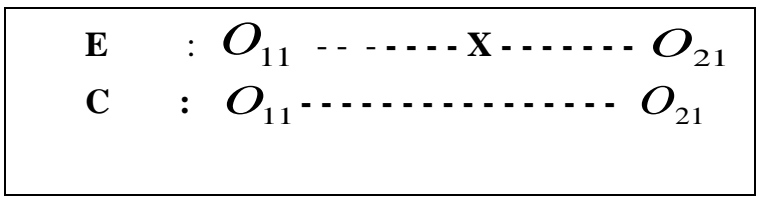

Figure 1. The research design 
In figure 1, $\mathrm{E}$ and $\mathrm{C}$ are the experimental and control groups, respectively. The two groups were given a pretest and a posttest. The symbol $\mathrm{X}$ represents the experimental treatment that was given to group E.The symbol $O_{11}$ represents the pretest (Achievement Test in Differential Calculus) which was administered to the two groups prior to the intervention, while the symbols $\mathrm{O}_{21}$ represent the posttest that was given after the intervention

\section{Subjects of the Study}

This study utilized two (2) existing classes, first trimester, AY 2015-2016 in Math 406 (Differential Calculus with Analytic Geometry).

The overall groups mean (pretest score on the achievement test) was computed to ensure the comparability of the control and experimental groups at the start of the experiment.

\section{Instrument Used}

Qualitative and quantitative data were gathered using the following instruments:

Achievement Test in Differential Calculus. A validated Achievement Test (teacher-made test) lifted from The Calculus 7(Leithold, 1996) was used in this study. An item in the test represents a topic covered. It consists of algebraic and transcendental functions to be differentiated. The test consisted of ten (10) functions, two (2) marks each with twenty (20) as the highest possible score. This Achievement Test was used by Salazar's(2014) recent study.

The researcher made a scoring rubric written on the Achievement Test and answer key with corresponding marks was prepared by the researcher before marking. The test were checked and graded by the researcher using the University Grading System

Table 1. Achievement Test Scores Descriptions

\begin{tabular}{|c|c|c|c|}
\hline \multicolumn{4}{|c|}{ University Grading System* } \\
\hline Score & Grade Ratings & Grade Range & Achievement Level Interpretations \\
\hline 20 & $96-100$ & 1.00 & Excellent \\
\hline $18-19$ & $86-95$ & $1.25-1.50$ & Very Good \\
\hline 14- 17 & $69-85$ & $1.75-2.25$ & Good \\
\hline $10-13$ & $50-68$ & $2.50-3.00$ & Fair \\
\hline $\begin{array}{c}\text { Below } \\
10\end{array}$ & $0-49$ & 5.0 & Failed \\
\hline
\end{tabular}

*AMAIUB Student Handbook SY 20-11-2012

With respect to the working description of the gain scores on the achievement test scores, the following correspondence was used.

\begin{tabular}{|c|c|}
\hline \multicolumn{1}{|c|}{ Table 2. Gain Scores Descriptions } \\
\hline Gain Scores & Achievement Level Increase Descriptions \\
\hline $17-20$ & Very High Increase \\
\hline $13-16$ & High Increase \\
\hline $5-12$ & Average Increase \\
\hline $1-4$ & Low Increase \\
\hline
\end{tabular}

Math Journals - this instrument was adapted from Salazar's $(2012,2013,2014)$ studies which was the source of qualitative data to determine insights in regards to the method of teaching used by the researcher. Prompts focused on the method of teaching specifically on the teaching methods, grouping method used and the incentives given. The students were encouraged to answer the questions in paragraph or outline form in English. This was used to validate the results of the quantitative assessments.

Interviews. The interview was used to validate the results of the quantitative assessment of the students. This served as a source of qualitative data on the students. The interview was conducted informally by groups to increase the rapport in the discussion and minimize shyness among the interviewees. The interview questions focused on the method of teaching, grouping method and incentives given and follow-up questions. The Math journal served as the guide questions to confirm their answers and some follow-up questions. 


\section{Data Collection}

Two (2) existing classes in Math 406 (Differential Calculus with analytic Geometry) as regular load of the researcher were the source of data collected. However, matching was done to ensure comparability in terms of the mathematical ability of the students based on the result of the pretest. By lottery, the control group and the experimental group was determined.

As soon as the treatments were assigned, the researcher conducted an orientation on the processes of the study. Then, the pretest was conducted after the orientation. The students were reminded that the result of the pretest has no bearing on their grades. The researcher himself handled the two classes.Prior to the conduct of the experiment, a try-out was done for one(1) meeting, to familiarize and as much as possible make the students feel at ease with the new method.

The Math journal was given after the posttest. To motivate them to answer the questions on the journal, the researcher has given incentives, which are additional points for their class participation grade. The posttest was considered as a formative test, open notes. To control other factors that might influence the outcomes of the study, the amount of time for conducting the two classes was two and one-half hours. Differentiations of algebraic and transcendental functions (explicit and implicit) were the coverage of the experiment. Both groups were provided with course specifications and instructional materials thru the moodle of the University. PowerPoint presentations were prepared and the methods of grouping differ.

\section{The Intervention}

Direct Method of Instruction was used to both groups .However, on the seatwork stage Salazar's Method of grouping was used in the experimental exposed to video captured lectures.

The actual lectures in the control group was recorded and been watched by the experimental group during class hours and were uploaded in the face book closed group page. The members of the closed group can view the video captured lectures anytime they like.

The control group was exposed to a regular lecture and the experimental group was exposed to the video captured lectures from the control group with Salazar's Method of grouping.

The sequence of activities for both groups is outlined below:

I. Introduction/Review - setting the stage for learning.

II. Development - explaining/deriving the formula and giving illustrative examples

III. Guided Practice- solving a problem with the student on the board, the teacher just acted as a secretary.

IV. Closure- making a summary on the lesson emphasizing the important points.

V. Seatwork - a set of problems were given to the board where the students solve the problems ( one problem at a time) using the following method of grouping.

Salazar's Method of Grouping. The first stage is the Individual Learning. As soon as the student successfully defended his solution in class and earned the teacher signatures, he was instructed to select a group member of his choice and then proceed to the next problem. Whenever, the same group (with two members) was able to defend their solution in class successfully, each group member earned the teacher signature. Then, they must select another group member of their choice and moved to the next problem. Solving the problem was a group effort .If again, the group with three (3) members successfully defended their solution, and each group member earned the teacher signature, and then returns to stage one. This cycle continued until the end of the experiment. However, membership of groups must not be the same on the next groupings. When all the students have belong to a group of two or three, the said group returned to stage one. The accumulated signatures were converted to additional points and added to students' final project raw scores and/or class participation raw scores.

The posttest was administered after the experiment. The math journal was given a day before the posttest. As soon as the students submitted their Math journal, follow-questions was asked (interview) to the subjects of the study. 


\section{Data Analysis}

Both quantitative and qualitative analyses were done to determine the achievement level of the respondents who were exposed to the two groups. The quantitative data were derived from the math journals and follow-up interview results.

The pretest raw scores of the two groups were used to determine the comparability of the subjects. The $t-$ test was used to test the significance difference between and within groups' pretest/ posttest results and also with gain scores.

The Vassar Stats: Website for Statistical Computations ( http://faculty.vassar.edu) was used in the statistical computation.Hypothesis was tested using 0.05 level of significance.

\section{Results and Findings}

The following discussion presents the results of the analysis of the student scores in the Achievement Test in

Differential Calculus. It describes the effects actual video captured lectures on the student's achievement level.

This result was supported by the qualitative data gathered from the math journal and follow-up interview

\section{Achievement Level}

Table 3 below presents the results of the pretest and posttest of the two groups.

Table 3. Comparison of Raw Scores in the Achievement Test

\begin{tabular}{|c|c|c|c|c|c|c|c|c|c|c|c|c|}
\hline \multirow{3}{*}{ Raw Score } & \multicolumn{6}{|c|}{ PRETEST } & \multicolumn{6}{|c|}{ POSTTEST } \\
\hline & \multicolumn{3}{|c|}{ Control Group } & \multicolumn{3}{|c|}{ ExperimentalGroup } & \multicolumn{3}{|c|}{ Control Group } & \multicolumn{3}{|c|}{ Experimental Group } \\
\hline & f & $\%$ & ITP & $\mathbf{f}$ & $\%$ & ITP & f & $\%$ & ITP & f & $\%$ & ITP \\
\hline 20 & & & & & & & & & & & & $\mathrm{E}$ \\
\hline $18-19$ & & & & & & & 1 & 3 & & 5 & 16 & VG \\
\hline $14-17$ & & & & & & & 5 & 16 & $\mathrm{G}$ & 19 & 59 & $\mathrm{G}$ \\
\hline $10-13$ & & & & & & & 16 & 50 & $\mathrm{~F}$ & 8 & 25 & $\mathrm{~F}$ \\
\hline Below 10 & 32 & 100 & FL & 32 & 100 & FL & 10 & 31 & FL & 0 & 0 & FL \\
\hline $\begin{array}{l}\text { Total } \\
\text { ( Mean) }\end{array}$ & 32 & 100 & $\begin{array}{l}\text { FL } \\
(0.5)\end{array}$ & 32 & 100 & $\begin{array}{c}\text { FL } \\
(1.1)\end{array}$ & 32 & 100 & $\begin{array}{l}\mathbf{F} \\
(\mathbf{1 1})\end{array}$ & 32 & 100 & $\begin{array}{l}G \\
(14)\end{array}$ \\
\hline $\begin{array}{l}\text { Grade } \\
\text { Equivalent }\end{array}$ & & & 5.0 & & & 5.0 & & & 2.75 & & & 1.75 \\
\hline
\end{tabular}

Legend: ITP - Interpretation- Excellent:VG- Very Good ;G - Good ; F-Fair; : FL- Failed

It can be gleaned from the table above, that both groups (control and experimental) has a mean score in the pretest is 0.5 and 1.1 respectively with a grade equivalent of 5.0, a failure grade. $100 \%$ of the students in the control group failed, in fact six (6) students got a score of four (4) and below out of twenty (20), the rest zero. While in the experimental group, thirteen (13) students got a score of five (5) and below, the rest zero, a 100\% failure. Therefore, the two groups are comparable at the very start of the study.

Further, the posttest in the control group obtained a passing mark of (2.75) with a mean score of 11 and the experimental group obtained a passing grade (1.75- interpreted as Good) with a mean score of 14. A mean gain score of 11 (interpreted as average increase) was obtained by the control group while the experimental group achieved a high increase of 14 marks. This results is better than the obtained gain score increase in Salazar's (2014) study. Although the respondents and intervention used was different.

Student's math journal revealed some reasons on their performance on the achievement test followed by their answers during the interview.

A student in the control group commented:

"I am bothered with tripod in front of the class and the limited space on the white board used to accommodate the videotaping of the lesson".

On the other hand, a student in the experimental group remarked:

"The video captured lecture was blurred and the sound was not clear. But the Doctor repeats and clarifies the lectures as needed". 
The teacher overheard a student saying: "No need with that video lecture, do it in the usual way!

However, one student commented:"The video captured lectures are very helpful, because it can be replayed many times until we understand. But, it would be better if video captured lectures were enhanced in terms of audio and visual presentations".

These observations confirm the advantages of using video captured lectures ( Gorissen, 2012).

Another student remarked that: "the grouping method was very helpful, it provides us an avenue to share our ideas, develop our communication skills and contributed to understanding the lesson'

Almost the same results were obtained in Salazar's (2014) study.

\section{Difference in Scores in the Achievement Test}

Table 4 presents the results on the test of significant difference of the scores in the achievement test within groups before and after exposing them to Video Captured Lectures.

Table 4. Difference of the scores in the achievement test within groups

\begin{tabular}{|cc|c|c|c|c|c|}
\hline \multicolumn{2}{|c|}{ GROUP } & Pretest & Posttest & df & Computed t & p-value \\
\hline Control $(\mathrm{n}=32)$ & & & & & & \\
& Mean & 0.5 & 11.44 & & & \\
& SD & 1.05 & 2.84 & 31 & -23.23 & $<0.001^{*}$ \\
\hline Experimental(n=32) & & & & & \\
& Mean & 1.125 & 14.75 & \multirow{2}{*}{31} & -24.01 & $<0.001^{*}$ \\
& SD & 1.7 & 2.3 & 31 & & \\
& & & & & \\
\end{tabular}

* Significant at $p<0.05$ level of significance

Table 4 revealed that there is significant differences on the student mean scores in their achievement test within groups. That is both groups posted significantly better scores after the exposure to video captured lectures, since the p-values are less than 0.05 .

Furthermore, Table 5 presents the results on the test of significant difference of the scores in the achievement test between groups before and after exposing them to Video Captured Lectures.

Table 5. Difference of the scores in the achievement test between groups

\begin{tabular}{|c|c|c|c|c|}
\hline GROUP & Posttest & df & Computed t & p-value \\
\hline Control $(\mathrm{n}=32)$ & $\begin{array}{c}11.375 \\
2.83\end{array}$ & & & \\
\hline Experimental $(\mathrm{n}=32)$ & $\begin{array}{c}14 \\
2.87\end{array}$ & 31 & -3.46 & $<0.0008^{*}$ \\
\hline
\end{tabular}

* Significant at $p<0.05$ level of significance

Results of the posttest between groups revealed that there is a significant difference of the scores in the achievement test. This results shows that video captured lectures with Salazar's Method of grouping is effective in raising students scores in the achievement test in Differential Calculus. Thus, using technology in the classroom is an effective tool in improving students' performance in mathematics (http://sites.google.com/she/teachingcalculus/). Furthermore, this result confirmed that enhanced grouping is an effective way in raising students' achievement in Mathematics ( Salazar, 2012;2013;2014).

\section{Gain Scores within Groups}

Table 6 exhibited an increase of scores in the Achievement test in both groups after exposing them to video captured lectures. As seen in table 6 above, the control group obtained an average mean increase of 11.58, while the experimental group obtained a high increase of 13.85. This result shows that video captured lectures contributed to this high increase of gain scores on students achievement scores in Differential Calculus. Only $3 \%$ 
(3 out of 32) obtained a very high increase within the range of 17-20 and $0 \%$ ( 0 out of 32) obtained a very low increase within the range of 1-4 in the control group, while in the experimental $16 \%$ (5 out of 32) got a very high increase (score range 17-20) and none got a very increase (score range of 1-4). This result indicates that using technology specifically video captured lectures is an effective method in improving students' performance (http://sites.google.com/she/teachingcalculus/).

Table 6. Gain Scores by Group

\begin{tabular}{|c|c|c|c|c|c|c|}
\hline Gain Scores Range & \multicolumn{3}{|c|}{ Control Group } & \multicolumn{3}{c|}{ Experimental Group } \\
\cline { 2 - 7 } & $\mathbf{f}$ & \% & ITP & f & \% & ITP \\
\hline $17-20$ & 1 & 3 & VH & 5 & 16 & VH \\
\hline $13-16$ & 11 & 34 & H & 19 & 59 & $\mathrm{H}$ \\
\hline $9-12$ & 12 & 38 & $\mathrm{~A}$ & 5 & 16 & $\mathrm{~A}$ \\
\hline $5-8$ & 8 & 25 & $\mathrm{~L}$ & 3 & 9 & $\mathrm{~L}$ \\
\hline $1-4$ & 0 & 0 & $\mathrm{VL}$ & 0 & 0 & $\mathrm{VL}$ \\
\hline $\begin{array}{c}\text { Total } \\
\text { (Mean) }\end{array}$ & $\mathbf{3 2}$ & $\mathbf{1 0 0}$ & $\begin{array}{c}\mathbf{A} \\
(\mathbf{1 1})\end{array}$ & $\mathbf{3 2}$ & $\mathbf{1 0 0}$ & $\begin{array}{c}\text { H } \\
(\mathbf{1 3 . 8 5})\end{array}$ \\
\hline
\end{tabular}

Legend: ITP-Interpretation ; VH-very high increase ; $H$-high increase ; A - average increase ; L-low increase ;

\section{Comparison of Gain Scores}

Table 7 presents the results on the test of significant difference of the gain scores in the achievement test between groups before and after exposing them to Video Captured Lectures.

Table 7. Comparison of gain scores

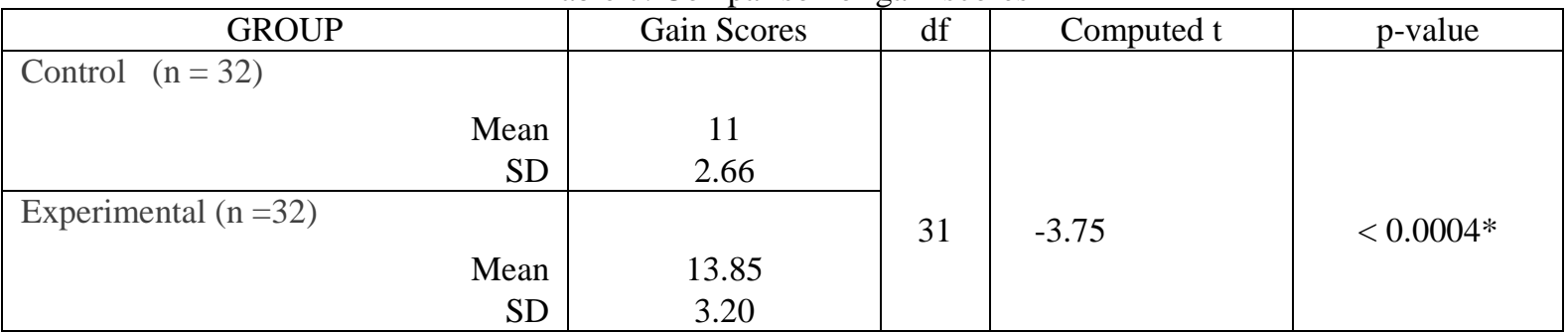

* Significant at $p<0.05$ level of significance

Results of the gain scores between groups revealed that there is a significant difference of the gain scores in the achievement test. This results shows that video captured lectures with enhanced groupings is effective in raising students scores in the achievement test in Differential Calculus. This results confirms the findings on the significant difference in scores between groups.

\section{Insights Drawn from Students Math Journal and Interview}

The following are insights drawn from students Math Journal and interview in terms of the researcher method of teaching, method of grouping and incentives given.

\section{Method of Teaching Used}

The students from the two groups (control and experimental) had written the following impressions and comments.

A student from the control group had written on his journal: "Video capturing of lectures must be done at the back of the classroom not in front. This process gives us an impression that the teacher is doing the lecture of for video purposes only"

Another student commented: "The doc uses only a very small space in solving problems. Only within the lights of the projector. We wait too long". 
While from the experimental group, a student said in his math journal: "The visual and audio presentation is bad! Not clear. The doctor sounds different in the video. But the teacher repeats the lectures on the video. It consume much time. However, when I view the video on the face book, I understand already. The video helps me. I repeat and repeat until I understand. However, some solutions were cut and can't be read in the video. So, I need to review my notes!"

Another student commented on the method of grouping used:"The grouping method is excellent; we have the chances to be group with other classmates and to help them. Also, the turnout of grouping is fast which means more signatures for us. The videos in the face book were very helpful as review materials for us".

Some students commented on the incentives given: "The incentives given is a good idea, however, some of the students are just copying the solutions and answers in order to get the teacher signature”.

This was controlled by the instruction by asking question before giving the incentives or asking them to explain their solutions in class.

One student was thankful of the incentives given: "Am very thankful because we can add more points in our project and class participation grade.. I will be very happy if these points will be added to our final exam score"

The incentives given served as a motivating factor to students to participate in class.

Most of the students considered the subject difficult, and one student wrote: "The teachers explains fast, he assumes that we are very good algebra, absorbs all what he explained in his presentations. He gives limited examples and the rest as seat works. We have worked doctor, wife and children! Good for you, you only work is same subject math. We just need to pass! Help us. We don't need calculus in our work!

Lastly, here are some of the general comments: "I believe that Dr. Douglas is just doing his job .If I asked him, he repeats and discuss again the topic. He is very accommodating when a student asked a question or help on how and why? Most of my classmates do not attend the class regularly and some just affixed their signature and go. I always heard him saying: Am just following the criteria in giving grades. Give me a passing mark on the major exams, for sure you will pass. Everything is solved and given to you...I just change the given. Please study!

And lastly, a student wrote: "Many students failed in this subject, this is my $4^{\text {th }}$ time, am graduating, so help me. I just need to pass".

The student responses to the Math Journal and Interview disclosed that they have tried their best to at least earn the teachers signature. They have developed the value of sharing and helping others during seat works. It promoted effective communication and exchange of ideas towards a common goal. The incentives made the seatwork enjoyable. This students comments were also revealed by the study of Salazar (2013). The findings of this study are presented below following the sequence of the research questions in the statement of the problem. 1. The pretest results of the two groups in the Achievement test showed mean scores of 0.5 and 1.1 for the control group and experimental groups, respectively. Both mean scores fall in the category of FAILURE. That is, they totally don't have any idea on how to differentiate functions even if the formulas are given. Most of the students scored below 10 out of 20. Majority got zero.

However, the Achievement Test mean score in the control group improved from 0.5 to 11 . That is from a grade of 5.0 to 2.75, a passing grade. However, in the experimental group, the achievement test mean score improved from 1.1 to 14 , that is from a grade of 5.0 to 1.75 , a passing grade, interpreted as Good performance.

2. Comparing the test scores within and between groups (experimental and control groups) revealed that there is a significant difference between pretest scores and posttest scores in both groups.

3. In the gain scores obtained within groups, the control group obtained a mean gain score of 11 interpreted as average increase while the experimental group revealed 13.85 mean gain score which is interpreted as high increase.

4. A significant difference of the gain scores between the two groups was revealed by the t- test.

5. The following insights were drawn from the students' math journal and follow-up interview:

They felt that Differential Calculus is difficult even before the prelim period. .They had poor background in the prerequisite subjects (algebra, trigonometry). Both groups were in favor of the sequence of presentation of the 
lesson used in this study especially on the incentives given. But on the actual video captured lectures, the experimental group suggested to enhance the audio and visual presentations of recorded videos of the Doctor. The uploaded video captured lectured help them to understand better the subject because the can replay the video anytime and anywhere. The enhanced grouping encouraged them to solve problems by themselves, share and help others in the next stages. The incentives served as a driving force to solve the problems on the seatwork stage. While in the control group, the process of videotaping the actual lecture was an eyesore to them.

\section{Conclusion}

It is therefore possible to increase the gain scores of the students using video captured lectures with enhanced groupings as used in this study.

Although, the result revealed a failure mark on the pretest but a significant increase of the scores and gain scores was achieved in the posttest. Specifically, an average and high increase was gained which obtained a passing mark of 2.75 and 1.75 (control and experimental group, respectively). Insights drawn from the students' journal that can contribute more in raising students' achievement in Differential Calculus deserve an attention, which is an enhanced video captured lectures of the professor rather than the unedited actual video captured lectures.

\section{Recommendations}

On Poor Preparation in Differential Calculus. It is recommended that there must be strong foundations on students' pre-requisite skills, specifically on algebra. College Algebra must be five (5) units' subjects. Engineering and Computer science students must not be combined with business students in College Algebra. Remedial Math for engineering and computer science must be different with the business students. Strict implementation on the policy of accepting new students must be considered.

On Future Researches. For future researches, the following could be considered;

Use of homogeneous or heterogeneous small grouping according to ability levels, gender type, reverse order of grouping used in this study, or other types of grouping. Use of large class method of teaching mathematics.Development of enhanced video instructional materials in Calculus that can be uploaded in the moodle. Researches in using Mathematical Software i.e MATLAB, MATHWAY, SYMBOLAB, etc.Calculus is viewed by the students as the most difficult mathematics subjects by AMAIUB students. Unless a strong foundation on its pre-requisite skills is achieved, the students' performance in Differential Calculus will still be low. Our students are interested to learn, but they are NOT ready to learn.

\section{References}

Bagarukayo,E., van der, Weide, T. and W.A. Mbarika, V. (2011). Impact of video recorded lectures on learning at Radboud University, Netherlands. Retrieved, October ,2014 from

http://www.globdev.org/files/Shanghai\%20Proceedings/13\%20REVISED\%20BagarukayoImpact\%20of\%20Vid eo.pdf

http://faculty.vassar.edu

Leithold, Louis (1996). The calculus 7. Harper Collins Publisher Inc .New York

Teaching calculus using technology. Retrieved October, 2014 from https://sites.google.com/site/teachingcalculus1/

Salazar, D. (2013). Grouping methods in a flipped classroom environment; effects on students achievements in differential calculus. AMA International University- Bahrain

Salazar, D. (2012). Razalas Method of groupings: effects on students achievements in integralcalculus.RetrievedOctober,2014 http://www.academia.edu/12258770/RAZALAS_METHOD_OF_GROUPING

Salazar, D. (2011).Salazar's Grouping Method: Effects on student achievement in integral calculus. Retrieved

October, 2014 from http://www.academic-publications.com/publication/p/fe6d89c1ebbb9bba/t/Salazar-sGrouping-Method

White, D. (2014). What is lecture capture? Retrieved October, 2014

http://panopto.com/blog/lecture-captureand-the-i-was-there-factor/ 